\title{
Change in Zeta Potential by Alternating Electromagnetic Treatment as Scale Prevention Process
}

\author{
Senshin UMEKI ${ }^{1}$, Takashi WATANABE ${ }^{2}$, Haruki SHIMABUKURO ${ }^{3}$, Takuya KATO ${ }^{3}$, \\ Noboru YOSHIKAWA ${ }^{4}$, Shoji TANIGUCHI ${ }^{4}$ and Kazuyuki TOHJI ${ }^{4}$ \\ ${ }^{1}$ Institute of Fluid Science, Tohoku University \\ 6-6-02 Aza Aoba, Aramaki, Aoba-ku, Sendai, Japan 980-8579 \\ Fax: 81-22-795-7302, e-mail: umeset@mail.tains.tohoku.ac.jp \\ ${ }^{2}$ Under Graduate Student at Tohoku University \\ ${ }^{3}$ Gradute Student at Tohoku University \\ ${ }^{4}$ Graduate School of Environmental Studies, Tohoku University
}

\begin{abstract}
The interface potential of microparticles in aqueous solution is an important factor for scale formation in a water piping. For application to scale prevention process, the influence of alternating electromagnetic field on the interface potentials of $\mathrm{CaCO}_{3}$ particles in the solution was investigated. Using a suspension of $\mathrm{CaCO}_{3}$ particles dispersed in an electrolytic solution, we measured zeta potential changes of the particles by imposition of weak alternating electromagnetic field at different frequency. Consequently, we found that the specific frequency treatment changes the interface potential of particles drastically with an inversion of its sign. It is considered to be due to the specific adsorption of anions in the solution on the particles interface by the effect of induced electric field.
\end{abstract}

Key words: zeta potential, calcium carbonate, colloid, scale, water, magnetic treatment

\section{INTRODUCTION}

In the last half century, a number of experiments have been conducted to study (electro) magnetic field effects on aqueous solutions. For example, magnetic field treatment of an aqueous solution was shown to suppress scale formation in water piping [1-5], as well as affect morphological changes during crystallization [6-12] and the solid-liquid interface [13-16]. However, these experiments were not always reproducible and contain mutually conflicting results [1]. These studies were performed for aqueous solutions that usually did not contain magnetic substances. The effects persist even after removal of the magnetic field and behave as if the water has a memory of the magnetic field. Water is a representative diamagnetic material and its magnetic susceptibility is $-9.07 \times 10^{-9} \mathrm{~m}^{3} \mathrm{~kg}^{-1}\left(20^{\circ} \mathrm{C}\right)[17]$. Therefore, the interaction between water and a magnetic field is so small that it can be disregarded. Since water does not have magnetic memory, such magnetic field effects have been considered to be mysterious phenomena.

We reviewed past reports concerning magnetic field effects on aqueous solutions in detail. The magnetic field effects were found to emerge remarkably when an alternating magnetic field was applied to an aqueous solution containing ions, particles, and other impurities. A number of papers have reported that an alternating magnetic field treatment produced a magnetic field effect even for weak magnetic field intensity not very different from geomagnetism $(50 \mu \mathrm{T})[5,10,18]$. According to recent reports, the magnetic treatment of water containing particles changes the thickness of the adsorption layer and the interface potential at the solid-liquid interface [13-16]. One report indicated that treatment using an alternating magnetic field was effective [14]. Studies of the magnetic field effects on aqueous solutions include several dealing with morphological changes of calcium carbonate during crystallization [6-12]. For such studies, the solid-liquid interface status can be considered to be important. One of the major issues for studies on magnetic field effects is the prevention of scale adhesion to water pipes and scale exchangers [1-5].

In our previous studies, we have found the effect of a weak alternating electromagnetic field on the interface potential of non-magnetic microparticles $\left(\mathrm{TiO}_{2}\right)$ in a liquid $[19,20]$. That is, the zeta potential values obviously change to negative direction by imposition of several $\mathrm{kHz}$ electromagnetic fields. This effect is considered to be due to the specific adsorption of anions that were easily adsorb to solid/liquid interface. Therefore, we consider the effect of scale prevention by alternating electromagnetic treatment as follows: In the scale formation condition, a surface of scale particles in water solution has positive charge. A surface on inner wall of a water pipe has negative charge, on the contrary. So the particles are attracted by the 
water pipe and attached to it. After the treatment, surface potential of the particles shifts to negative direction, then repulsive force is formed between the particles and the wall.

Since main component of scale deposits is generally calcium carbonate, we need to measure the zeta potential of $\mathrm{CaCO}_{3}$ particles in aqueous solution. However, the measurement of the zeta potential of $\mathrm{CaCO}_{3}$ by commercially produced zeta potential meter is not so easy, because equi-sized colloidal particles are not available, and they easily coagulate in aqueous solution. Therefore we estimated the interface potential of $\mathrm{CaCO}_{3}$ by the handmade simple electrophoresis cell.

\section{EXPERIMENT}

Using a suspension of $\mathrm{CaCO}_{3}$ particles dispersed in an electrolytic solution, we investigated interface potential changes of the particles by alternating electromagnetic field treatment at different frequency. An electrolyte was added to a commercial ion-exchange water (measurement: about $2 \mathrm{M} \Omega \mathrm{cm}$ ). Immediately before each measurement, the solution was used to suspend $\mathrm{CaCO}_{3}$ powder $(0.2 \mathrm{wt} \%)$ which was mashed well in a mortar. The $\mathrm{pH}$ of the suspension was almost stable at 9.7 to 9.9 for $10 \mathrm{mM} \mathrm{KCl}$ and 10.2 to 10.4 for $10 \mathrm{mM} \mathrm{KF}$.
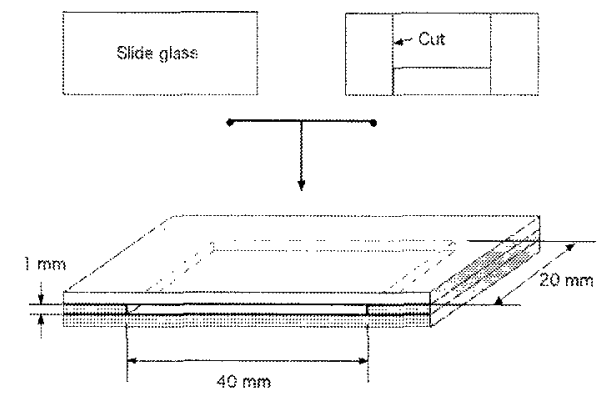

Fig. 1 Schematic diagram of the handmade electrophoretic cell

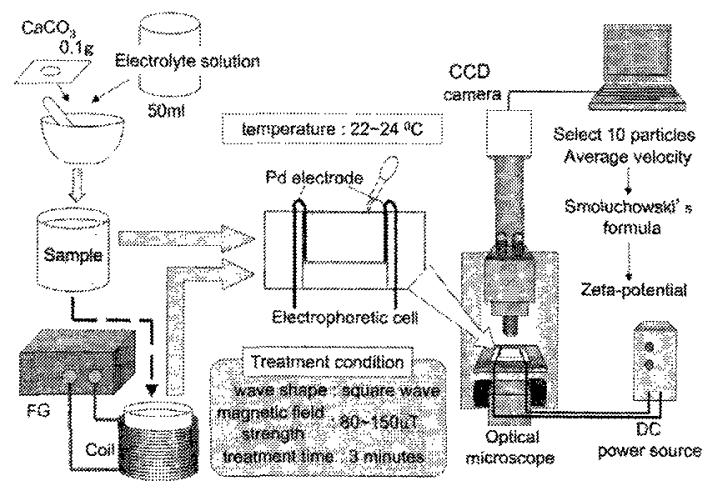

Fig. 2 Experimental procedure for observing electrophoresis ("FG" means a "Function generator")

An alternating electromagnetic field was generated by using a "Function generator" (NF Co., Ltd., WF1944A) with a handmade coil ( $\phi: 88 \mathrm{~mm}, 1: 91 \mathrm{~mm}$,
460 windings). The electromagnetic field intensity was about $80 \mu$ to $150 \mu \mathrm{T}$ at the center of the coil. The experimental results in this paper are based on a square-wave electromagnetic field of $1 \mathrm{k}$ to $10 \mathrm{kHz}$ according to our previous experiments $[19,20]$. If a square-wave is applied to such a coil, a waveform disorder tends to generate an electromagnetic field at the unexpected frequency. Therefore, the voltage applied to the coil is adjusted to minimize any unintended electromagnetic field caused by disorder at each frequency, and the target electromagnetic field intensity was set to about $100 \mu \mathrm{T}$. Similar results were also obtained when a sine-wave electromagnetic field was applied. The electromagnetic field was applied for three minutes to the specimen kept still at room temperature $\left(22\right.$ to $24^{\circ} \mathrm{C}$ ).

The interface potential measurement method is a simple technique to observe particles migrating in a handmade electrophoretic cell under a microscope and calculating the potential from their mobility [21]. The $40 \mathrm{~L} \times 20 \mathrm{~W} \times 1 \mathrm{~T} \mathrm{~mm}$ electrophoretic cell was fabricated by affixing three piece of appropriately cut Pyrex object glass (Fig. 1) and Pd wire ( $\phi: 0.8 \mathrm{~mm}$ ) was connected to each end. The specimen solution was gently poured into this cell. The cell was then placed horizontally in an optical microscope and $10 \mathrm{~V}$ was applied between the electrodes. Figure 2 shows the experimental set up for observation of electrophoresis. Particles electrophoresis was carried out and recorded by a CCD camera through the optical microscope.

An untreated specimen is measured first and then treated after storage in an alternating electromagnetic field of a specific frequency. After the treatment, a similar measurement was performed immediately.

\section{RESULTS AND DISCUSSIONS}

Figure 3 shows the electrophoresis of particles. Fig. $3 \mathrm{a}$ is a movie image obtained by a CCD camera through a microscope. Black dots in the image are $\mathrm{CaCO}_{3}$ particles. An electric field of about $250 \mathrm{Vm}^{-1}$ was applied from the left to the right in the image. We chose arbitrary particles from this image and observed their movement. Figs. 3b and 3c (Fig. 3 a corresponds to Fig. $3 \mathrm{~b}$ at $0 \mathrm{sec}$.) image-processed from Fig. $3 \mathrm{a}$ show the positions of these particles 30 seconds later.

In this experiment, a suspension ( $\mathrm{pH} 9.7$ to 9.9 at $25^{\circ} \mathrm{C}$ ) of $\mathrm{CaCO}_{3}$ particles dispersed in $10 \mathrm{mM} \mathrm{KCl}$ solution was used. Before the treatment (Fig. 3b), the particles moved towards the cathode. This indicates that the particles had positive zeta potential. After the treatment at $7 \mathrm{kHz}$ (Fig. 3c), however, the particles moved towards the anode. This clearly indicates that the treatment reversed the zeta potential from positive to negative.

We chose 10 arbitrary particles from this image and calculated the mobility $u$ from their average speed. As the particles have a radius large enough for the thickness of the electric double layer, similar to colloidal particles, Smoluchowski's formula given below is known to be applicable to particles of arbitrary forms [22].

$$
u=\varepsilon_{0} \varepsilon_{\mathrm{r}} \zeta / \eta
$$


Here, $\varepsilon_{0}, \varepsilon_{\mathrm{r}}$, and $\eta$ are the permittivity in vacuum, the relative permittivity and viscosity of the solution, respectively. Using this formula, the zeta potential $\zeta$ of the particles can be obtained.

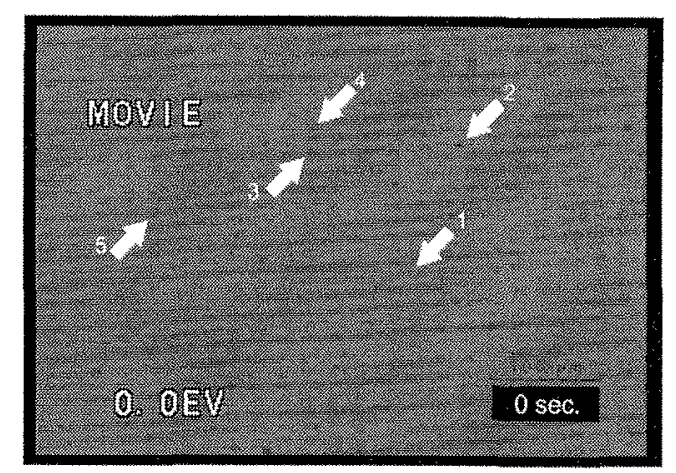

Fig. 3a Micrograph obtained by the CCD camera (image from a movie)

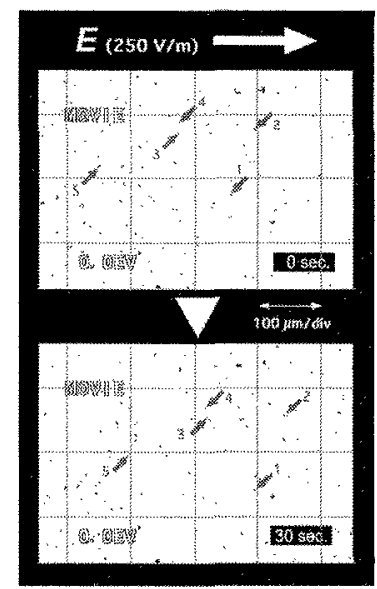

(b)

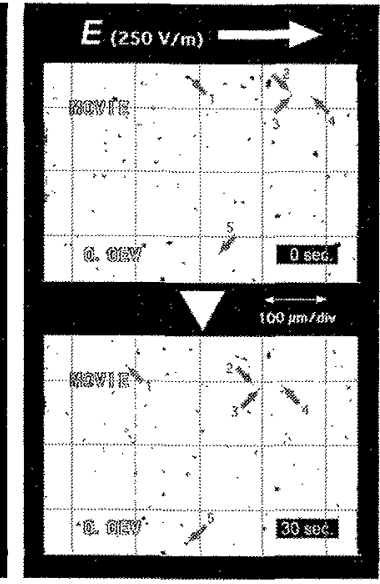

(c)
Fig. 3b Processed images of 30-second particle electrophoresis without electromagnetic treatment (b), after $7 \mathrm{kHz}$ treatment (c)

Figure 4 shows the change in the zeta potential at different treatment frequencies. It can be seen that treatment at $6 \mathrm{kHz}$ or higher frequency drastically changed the zeta potential of the particles towards a negative value. The change of the potential is $10 \mathrm{mV}$ or more, including the reversal of the sign. This was reproduced ten times in the study for each case.

The charging of $\mathrm{CaCO}_{3}$ in the liquid can be attributed mainly to the concentration of potential determining ions $\left(\mathrm{Ca}^{2+}, \mathrm{CO}_{3}{ }^{2-}, \mathrm{HCO}_{3}{ }^{-}, \mathrm{H}^{+}\right.$and $\left.\mathrm{OH}^{-}\right)$in the solution [23]. Since the $\mathrm{pH}$ of the solution used in this experiment did not change after the treatment, however, changes in the interface potential could likely be attributable to a different charging mechanism. The specific adsorption of anions to the particle interface may be the charging mechanism producing such changes. The electrolytic solution used here was $10 \mathrm{mM} \mathrm{KCl}$ and therefore, most of the ions in the solution were $\mathrm{Cl}^{-}$and $\mathrm{K}^{+} . \mathrm{Cl}^{*}$ ions in liquid are weak in hydration because of the large ion radius and are known to be easily adsorbed onto a solid interface, compared with the $\mathrm{K}^{+}$ions [24]. Therefore, changes in the zeta potential measured in this experiment can be attributed to the specific adsorption of $\mathrm{Cl}^{-}$ions to the particle interface.

Figure 5 shows the zeta potential changes between un-treatment and after $7 \mathrm{kHz}$ treatment at different density of $\mathrm{KCl}$ solutions. This graph tells us that the density of the electrolyte must be certain level and above for the effect occurs. When a similar experiment was conducted with $\mathrm{KF}$ as the supporting electrolyte instead of $\mathrm{KCl}$, the zeta potential did not change largely (Fig. 6). Compared with $\mathrm{Cl}^{-}$ions, $\mathrm{F}^{-}$ions are small in radius. Because of the strong hydration structure, $F^{-}$ions are hardly adsorbed [24]. This also indicates that changes in the interface potential by the alternating electromagnetic field treatment can be attributed to the adsorption of $\mathrm{Cl}$ ions.

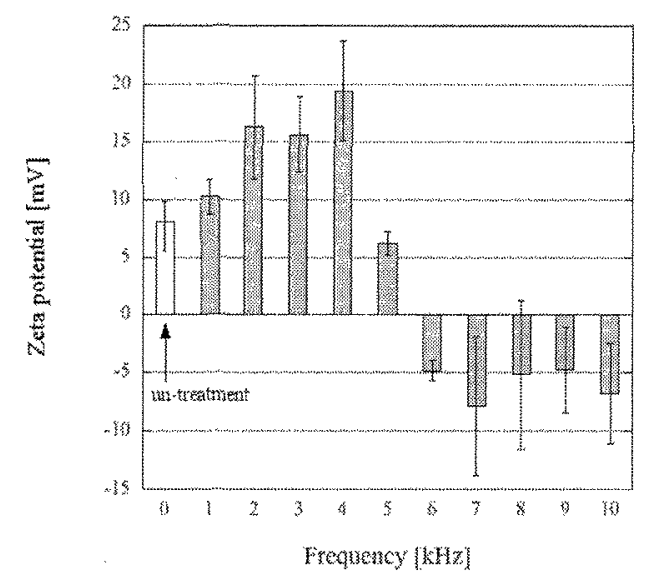

Fig. 4 Dependence of the zeta potential of $\mathrm{CaCO}_{3}$ particles $(10 \mathrm{mM} \mathrm{KCl})$ on the treatment frequency (Error bar represent the maximum error)

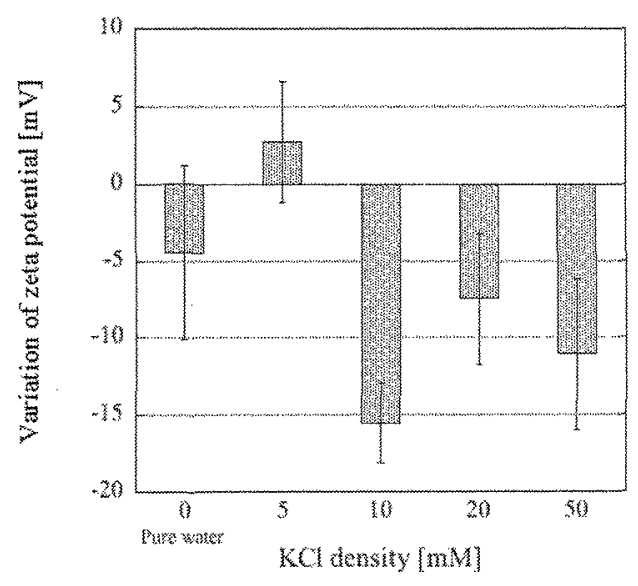

Fig. 5 The zeta potential changes between un-treatment and $7 \mathrm{kHz}$ treatment at different $\mathrm{KCl}$ electrolyte density 


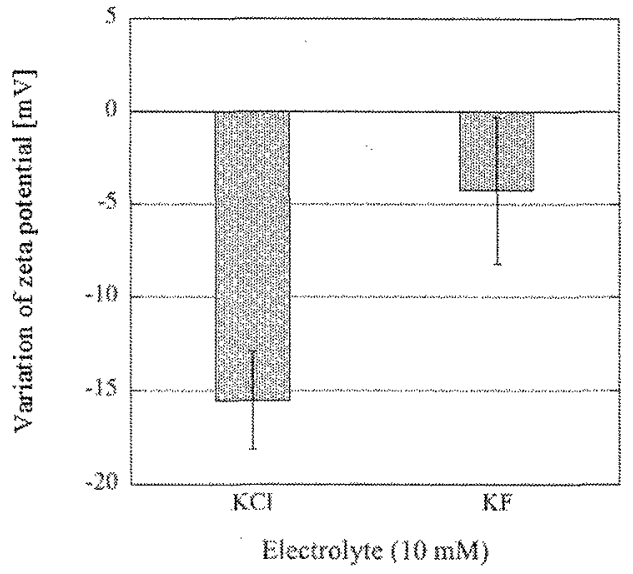

Fig. 6 Variation of the zeta potential $(7 \mathrm{kHz}$ treatment) on different electrolyte type

\section{CONCLUSION}

The above results confirmed a drastic change in the interface potential of $\mathrm{CaCO}_{3}$ particles by the alternating electromagnetic field treatment at specific frequency (several $\mathrm{kHz}$ range). This change was attributed to the specific adsorption of anions, which were easily adsorbed, in the solution. These results indicate what is the essence of the mysterious magnetic field effects on aqueous solutions. However, the mechanism by which the treatment produces specific adsorption to the particles interface is still unknown. Since the interactions among water, ions, and calcium carbonate particles, and a magnetic field are very small, this could be due to an induced electric field (rot $\mathbf{E}=$ $-\mathrm{d} \mathbf{B} / \mathrm{dt}$ ) accompanying the magnetic field variation. This phenomenon obviously depends on the frequency. Therefore, an electromagnetic field of several $\mathrm{kHz}$ was found to affect the hydrated water structure of the solid-liquid interface.

From this experimental result, it seems reasonable to conclude that the alternating electromagnetic treatment is effective for prevention of scale. In addition, the results in this study not only clarify magnetic field effects on aqueous solutions but could also lead to completely new applications. For example, the findings may be useful for applying selective adsorption of ions in materials science as well as for clarifying the influence of an electromagnetic field on a human body. Furthermore, the findings may find uses in all interface-related fields.

\section{ACKNOWLEDGMENT}

This work was supported by $21^{\text {st }}$ century COE program, Tohoku University "International COE of Flow Dynamics" and Tohoku Steel Co. Ltd., by "ARECS" program, Dept. of Materials Science and Engineering, Tohoku University. We also thank Dr. S. Usui (Prof. Emeritus of Tohoku Univ.), Dr. I. Mogi (IMR, Tohoku Univ.), Mr. H. Otani and Mr. T. Fujino (Techno Labo Ltd., Saitama, Japan) for helpful discussion.

\section{REFERENCE}

[1] V. I. Klassen, "Magnetic Water Treatment", Khmiya, Moscow (1982).

[2] J. S. Baker and S. J. Judd, Water Research, 30 , 247-260 (1996).

[3] A. T. Pilipenko, I. G. Vakhim, V. I. Maksin and Z. A. Samchenko, Soviet J. Water Chem. Technol, 13, 45-64 (1991).

[4] C. Gabrielli, R. Jaouhari, G. Maurin and M. Keddam, Water Research, 35, 3249-3259 (2001).

[5] Y. I. Cho, C. Fan and B. Choi, International J. Heat and Mass Transfer, 41, 2961-2966 (1998).

[6] L. Pandolfo, R. Colale and G. Paiaro, Chim. Ind., 69 , 88-89 (1987).

[7] F. T. Ellingsen and H. Kristiansen, Vatten, 35 , 309-315 (1979).

[8] K. Higashitani, A. Kage, S. Katamura, K. Imai and S. Hatade, J. Colloid Interface Sci, 156 , 90-95 (1993).

[9] S. Knez and C. Pohar, J. Colloid Interface Sci., 281, 377-388 (2005).

[10] K. J. Kronenberg, IEEE Tras. Magn., 21, 2059-2061 (1985).

[11] S. Kobe, G, Drazic, A. C. Cefalas, E. Sarantopoulou and J. Strazisar, Crystal Engineering, 5, 243-253 (2002).

[12] J. M. D. Coey and S. Cass, J. Magnetism and Magnetic Materials, 209, 71-74 (2000).

[13] K. Higashitani and J. Oshitani, J. Colloid Interface Sci., 204, 363-368 (1998).

[14] J. Oshitani, R. Uehara and K. Higashitani, $J$. Colloid Interface Sci., 209, 374-379 (1999).

[15] L. Holysz, M. Chibowski and E. Chibowski, Colloids and Surface A, 208, 231-240 (2002).

[16] E. Chibowski, L. Holysz and A. Szczes, Colloids and Surface A, 222, 41-54 (2003).

[17] R. Cini and M. Torrini, J. Chem. Phys., 49, 2826-2830 (1968).

[18] K. Mohri and M. Fukushima, IEEE Trans. Magn., 38, 3353-3355 (2002).

[19] S. Umeki, T. Kato, H. Shimabukuro, N. Yoshikawa and S. Taniguchi, Trans. Materials Res. Soc. Japan, 31, 307-310 (2006).

[20] S. Umeki, T. Kato, H. Shimabukuro, N. Yoshikawa, S. Taniguchi, S. Usui, H. Otani and T. Fujino, Proc. The $5^{\text {th }}$ International Symposium on Electromagnetic Processing on Materials, 2006 , Sendai, Japan, ISIJ, 694-699 (2006).

[21] S. Usui, Kinzoku, 70, 993-998 (2000).

[22] A. Kitahara, K. Hurusawa, M. Ozaki and H. Ohshima, "Zeta Potential", Scientist-sya, Tokyo, (1995).

[23] P. Moulin and H. Roques, $J$. Colloid Interface Sci., 261, 115-126 (2003).

[24] J. O'M. Bockris, M. A. V. Devanathan and K. Muller, Proc. Royal Soc. London A, 274, 55- 79 (1963).

(Received January 20, 2007; Accepted May 10, 2007) 